\title{
Mycobacterium kubicae sp. nov., a slowly growing, scotochromogenic Mycobacterium
}

\author{
Margaret M. Floyd, ${ }^{1}$ Wendy M. Gross, ${ }^{2}$ Donald A. Bonato, ${ }^{2}$ \\ Vella A. Silcox, ${ }^{1} \dagger$ Ronald W. Smithwick, ${ }^{1}$ Beverly Metchock, ${ }^{1}$ \\ Jack T. Crawford ${ }^{1}$ and W. Ray Butler ${ }^{1}$
}

Author for correspondence: Margaret M. Floyd. Tel: +1 404639 1280. Fax: +1 4046391287. e-mail:mmf1@cdc.gov

\footnotetext{
1 Division of AIDS, STD and TB Laboratory Research, National Center for Infectious Diseases, Centers for Disease Control and Prevention, Atlanta, GA 30333, USA

2 VA Reference Laboratory for Tuberculosis and Other Mycobacterial Diseases, Department of Veterans Affairs, West Haven, CT 06516, USA
}

\begin{abstract}
A previously uncharacterized, slowly growing, scotochromogenic Mycobacterium species was detected by HPLC analysis of the cell-wall-bound mycolic acids. The mycolic acid pattern standard was shown to be a lateeluting, contiguous peak cluster occurring at approximately 8-9 $\mathrm{min}$. The mycolic acid pattern was noted to be most similar in number of peaks and range of elution to that reported previously for Mycobacterium asiaticum. However, the relative distribution of peaks within the elution range demonstrated a pattern with prominent peaks that started to emerge later than the characteristic $M$. asiaticum pattern. Standard biochemical identification test results were similar to those of the photochromogenic species $M$. asiaticum. Comparative 16S rRNA gene sequence analysis confirmed the genetic uniqueness of the strains and demonstrated the unclassified mycobacteria to be in a unique, intermediate position between slow and rapid growers in the phylogenetic tree of Mycobacterium. The name Mycobacterium kubicae sp. nov. is proposed for this taxon. The type strain is CDC $941078^{\top}$ $\left(=\right.$ ATCC $700732^{\mathrm{T}}=$ CIP $\left.106428^{\mathrm{T}}\right)$.
\end{abstract}

Keywords: Mycobacterium kubicae, mycolic acids, HPLC

\section{INTRODUCTION}

Conventional biochemical tests for identification of mycobacteria were designed primarily to detect and identify Mycobacterium tuberculosis and clinically important nontuberculous mycobacteria (NTM) (Kent \& Kubica, 1985). These tests have been extensively employed by clinical laboratories and have been shown to be valuable benchmarks for species identification. However, with the increasing number of newly defined taxa and the recognition of "difficult-toidentify' variants of known species, the tests are proving insufficient for identification (Kirschner et al., 1993).

In the United States, mycobacteriology reference laboratories with special expertise, like those at the

\footnotetext{
†Present address: 7215 Heard Road, Cumming, GA 30041, USA.

Abbreviations: NCP, no common pattern; NTM, nontuberculous mycobacteria; MAPS, mycolic acid pattern standards.

The GenBank accession number for the 16S rRNA gene sequence of Mycobacterium kubicae is AF133902.
}

Centers for Disease Control and Prevention (CDC), frequently analyse such isolates. The standard method for identification is HPLC analysis of mycolic acids. This rapid and simple chromatographic method replaced standard biochemical tests as the primary tool for identification of Mycobacterium species at CDC in 1990. After using this method for several years, it was recognized that an extensive number of mycobacteria presented non-representative chromatographic patterns when compared to mycolic acid pattern standards (MAPS) of well-characterized species (Butler et al., 1996, 1999). To facilitate communication of the occurrence of these unusual NTM to clinical laboratories the CDC Mycobacteriology Laboratory has used the following designations: (i) mycobacteria with unique mycolic acid patterns, reported as no common pattern (NCP); (ii) groups of 10 or more mycobacteria with matching patterns, reported as NCP with a assigned laboratory number; and (iii) mycobacteria with patterns that resembled known species, reported as NCP with an assigned laboratory number and as having a likeness to a known species. Described here are a group of NTM strains that initially were detected 
by HPLC and reported as NCP 216 and Mycobacterium asiaticum-like.

\section{METHODS}

Strains. The strains used in the study were submitted to CDC as 'difficult-to-identify' isolates by state mycobacteriology laboratories from 1994 to 1997. They were recovered from $-70{ }^{\circ} \mathrm{C}$ storage by subculturing to Lowenstein-Jensen $(\mathrm{L}-\mathrm{J})$ slants and Middlebrook-Cohn $7 \mathrm{H} 9$ broths (Remel) incubated at $37^{\circ} \mathrm{C}$. Characterization and reproducibility studies were done with 15 strains that exhibited a common HPLC pattern.

Phenotypic tests. Before comprehensive testing was initiated, strains were cultured in Middlebrook-Cohn 7H9 broth for 1 week. The 7H9 culture was streaked on Middlebrook-Cohn $7 \mathrm{H} 10$ and incubated for 3 weeks, and growth was examined at $\times 30$ magnification for purity. Growth studies were performed on $\mathrm{L}-\mathrm{J}$ and Middlebrook-Cohn 7H11 media incubated at $28,33,37$ and $42{ }^{\circ} \mathrm{C}$ for 8 weeks. Colony morphology and pigment production were observed on both media types after 3 weeks incubation at $37^{\circ} \mathrm{C}$. Cell morphology was determined from multiple smears prepared by the Kinyoun acid-fast method (Kinyoun, 1915) at $\times 1000$ magnification.

Previously described methods (Kent \& Kubica, 1985) were used to determine the standard biochemical reactions for these strains. A representative strain was selected based on biochemical test results and deposited in the American Type Culture Collection as the type strain. Phenotypic tests were performed for scotochromogenic mycobacteria and included an initial description of morphology and pigment production, nitrate reduction and Tween hydrolysis. Other enzymic reactions included catalase production, arylsulfatase and urease.

Antimicrobial susceptibility testing was determined by the agar proportion method on 7H10 medium (Kent \& Kubica, 1985).

Mycolic acid analysis. Mycolic acids were analysed by TLC and HPLC. The whole cells were saponified in $25 \%$ methanolic $\mathrm{KOH}$ for $1 \mathrm{~h}$ in an autoclave at $121^{\circ} \mathrm{C}$. The saponified mixture was acidified and the mycolic acids were extracted by the addition of chloroform. For the TLC procedure, the mycolic acids were methylated with freshly prepared diazomethane and spotted onto two silica gel F254 plates. One plate was developed with dichloromethane and the other with petroleum ether. Mycolic acids were visualized by spraying with $0.01 \%$ ethanolic rhodamine as described previously (Lévy-Frébault et al., 1986). For the HPLC procedure, mycolic acids were derivatized to bromophenacyl esters with para-bromophenacyl-8 (Pierce). The derivatized samples were separated by reverse-phase HPLC with a C-18 column using a gradient elution of methanol and methylene chloride as described previously (Butler et al., 1996).

$16 S$ rDNA sequencing. Cells suspended in buffer were disrupted with siliconized zirconium beads by vigorous shaking to obtain aqueous extracts containing chromosomal DNA. PCR amplification of the $16 \mathrm{~S}$ rRNA gene region was done with oligonucleotides 5'-GAGAGTTTGATCCTGGCTCAG-3' and 5'-AAGGAGGTGATCCAGCCGCA-3' as described previously (Edwards et al., 1989; Rogall et al., 1990). Direct sequencing of the $16 \mathrm{~S}$ rDNA amplicon was performed using a Taq DyeDeoxy terminator cycle sequen- cing kit (Applied Biosystems) with an Applied Biosystems model 373A DNA sequencer, following the instructions of the manufacturer. Overlapping DNA segments from both the forward and reverse strands were analysed to determine a consensus sequence for the $16 \mathrm{~S}$ rDNA. The analysis was repeated multiple times from single colony isolates. Consensus sequence data were compared to $16 \mathrm{~S}$ rDNA sequence information in GenBank using the FASTA algorithm from the Wisconsin Package for Sequence Analysis [Genetics Computer Group (GCG)]. The GCG program PILEUP was used to create a multiple sequence alignment from related sequences in GenBank. To properly align the sequences it was necessary to truncate 4 nucleotides at the start of the consensus sequence and 11 at the end, leaving 1317 bases for analysis. Version 3.5c of the Phylogeny Inference Package (PHYLIP; Felsenstein, 1985, 1993) was used for evolutionary analysis. Programs used for the analysis included: DNADIST, for calculation of a distance matrix on the nucleotide substitution using the model of Jukes \& Cantor (1969); NEIGHBOR, for construction of a tree using the neighbourjoining method; SEQBOOT, for bootstrap analysis of 100 replicates; and CONSENSE, for generation of a majority rule consensus tree representative of groups occurring in greater than $50 \%$ of all input trees.

\section{RESULTS AND DISCUSSION}

Geographically, the 15 isolates composing the study group originated from California, Florida, Georgia, Louisiana, Maryland, Oklahoma, Pennsylvania, Tennessee and Texas. The clinical source of four of the isolates were undetermined but eight were from sputum and three from bronchial washes. Additional clinical and strain history was not available.

Cells stained strongly acid-alcohol-fast, were rodshaped and frequently bent, but did not form filaments or branches. Occasional coccoid forms were noted. The estimated width ranged from 0.25 to $0.5 \mu \mathrm{m}$ and the length from 0.25 to $7 \cdot 0 \mu \mathrm{m}$. The optimal growth temperature was $37^{\circ} \mathrm{C}$. On Middlebrook-Cohn $7 \mathrm{H} 11$ medium, mature growth developed in 3 weeks at 28, 33 and $37^{\circ} \mathrm{C}$. Microcolonies developed in 2 weeks at these same temperatures. On L-J medium, microcolonies developed in 3 weeks but mature colonies were not noted until after 4 weeks of incubation at 33 and $37^{\circ} \mathrm{C}$. Thirteen of the fifteen isolates tested failed to grow on $\mathrm{L}-\mathrm{J}$ at $28^{\circ} \mathrm{C}$, and the remaining two isolates developed microcolonies after 3 weeks of incubation. None of the isolates grew on $\mathrm{L}-\mathrm{J}$ at $42{ }^{\circ} \mathrm{C}$. Overall, colonies grown on $7 \mathrm{H} 11$ were generally larger. Mature colonies were usually smooth, occasionally rough and always yellow in appearance. Cells lightly inoculated on $\mathbf{L}-\mathbf{J}$ medium grew film-like and produced a yellow pigment. The strains were negative in the $3 \mathrm{~d}$ arylsulfatase test and produced $>45 \mathrm{~mm}$ foam in the semiquantitative catalase test. They were negative for nitrate reduction and did not demonstrate enzymic hydrolysis of Tween 80 or urease activity (Table 1).

Standard biochemical reactions were homogeneous for the 15 strains, but were not completely distinctive when compared to other slow-growing mycobacteria. 
Table 1. Characteristics of 15 slow-growing strains composing the study group

\begin{tabular}{|c|c|}
\hline Characteristic & $\begin{array}{l}\text { Positive reaction/ } \\
\text { resistance }(\%)\end{array}$ \\
\hline \multirow{2}{*}{\multicolumn{2}{|c|}{$\begin{array}{l}\text { Growth on Middlebrook- } \\
\text { Cohn } 7 \mathrm{H} 11(21 \mathrm{~d}) \text { : }\end{array}$}} \\
\hline & \\
\hline $28,33,37^{\circ} \mathrm{C}$ & 100 \\
\hline $42^{\circ} \mathrm{C}$ & 0 \\
\hline \multicolumn{2}{|l|}{ Growth on L-J (28 d): } \\
\hline $28^{\circ} \mathrm{C}$ & 13 \\
\hline $33,37^{\circ} \mathrm{C}$ & 100 \\
\hline $42^{\circ} \mathrm{C}$ & 0 \\
\hline Arylsulfatase (3 d) & 20 \\
\hline Nitrate reductase & 0 \\
\hline Pigmented in the dark & 100 \\
\hline $\begin{array}{l}\text { Semiquantitative catalase } \\
\text { (45 mm foam) }\end{array}$ & 100 \\
\hline Tween 80 hydrolysis & 100 \\
\hline Urease & 0 \\
\hline \multicolumn{2}{|l|}{$\begin{array}{l}\text { Resistance to ( } \mu \mathrm{g} \mathrm{ml}^{-1} \text { in } \\
7 \mathrm{H} 10 \text { test medium): }\end{array}$} \\
\hline Amikacin $(6 \cdot 0)$ & 100 \\
\hline Ciprofloxacin $(1 \cdot 0,2 \cdot 0,4 \cdot 0,8 \cdot 0)$ & $100,93,33,6$ \\
\hline Clarithromycin $(3 \cdot 0)$ & 0 \\
\hline Clofazimine $(1 \cdot 0)$ & 0 \\
\hline Cycloserine $(25 \cdot 0,50 \cdot 0)$ & 66,0 \\
\hline Ethambutol $(10 \cdot 0)$ & 7 \\
\hline Ethionamide $(5 \cdot 0)$ & 0 \\
\hline Isoniazid $(0 \cdot 2,1 \cdot 0)$ & 100,20 \\
\hline Kanamycin $(6 \cdot 0)$ & 93 \\
\hline Rifabutin $(1 \cdot 0,2 \cdot 0)$ & 100,46 \\
\hline Rifampin $(5 \cdot 0)$ & 100 \\
\hline Streptomycin $(2 \cdot 0,10 \cdot 0)$ & 100,86 \\
\hline
\end{tabular}

Pigment production and growth rate were characteristic of Group II scotochromogens, by the classical Runyon Group Classification system. Overall, the biochemical results were most like the photochromogenic species $M$. asiaticum (Table 1). Results of drug susceptibility testing were unremarkable for differentiation of NTM and are shown in Table 1.

Alpha, keto and methoxy mycolates consistent with mycobacteria were detected by TLC (data not shown). This chemical association was confirmed with HPLC analysis by the elution of unique mycolic acids in the time range for mycobacteria. All 15 isolates analysed by HPLC produced a distinctive homogeneous mycolic acid group, for which a representative MAPS is shown in Fig. 1. The single cluster, seven-peak mycolate pattern was similar to the HPLC pattern reported previously with M. asiaticum (Butler et al., 1999). However, a difference in the overall time range of elution, calculated by comparison with the late emerging internal standard, was $1.12 \mathrm{~min}$ for the study isolates and $1.16 \mathrm{~min}$ for $M$. asiaticum. Additionally,

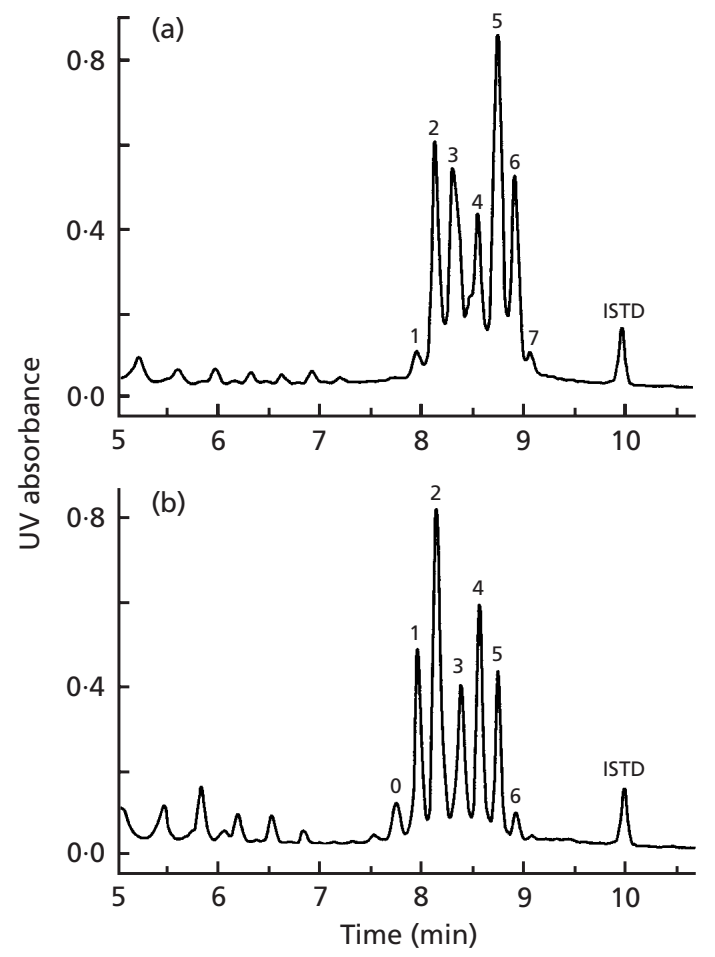

Fig. 1. Representative MAPS for the study isolates (a) and the phenotypically similar $M$. asiaticum (b). ISTD, internal standard.

differences were reflected by the relative heights of corresponding peaks in the patterns (Fig. 1): peak 1, $2 \cdot 3$ and $19.2 \%$; peak $2,19 \cdot 5$ and $31.2 \%$; peak $3,17 \cdot 2$ and $31.2 \%$; peak $4,13.4$ and $17.5 \%$; peak 5, 28.1 and $14.6 \%$; peak $6,16 \cdot 8$ and $2.25 \%$, for the study isolate and $M$. asiaticum, respectively. This disproportional amount of each peak detected by HPLC has previously been reported to be species-specific for mycobacteria (Butler et al., 1996, 1999; Duffey et al., 1996; Floyd et al., 1996; Glickman et al., 1994; Ramos, 1994; Thibert \& LaPierre, 1993; Tortoli et al., 1995; Wayne et al., 1996).

Initially, all isolates were screened genetically by determination of the species-specific signature region A in the 16S rRNA gene, reported to be representative of slowly growing mycobacteria (Stackebrandt \& Smida, 1988; Stahl \& Urbance, 1990; Rogall et al., 1990). This hypervariable region of approximately 139 nucleotides in the $5^{\prime}$ end of the gene was found to be identical for the study isolates and divergent from other mycobacteria (Fig. 2). The distinctiveness of the sequence pattern for signature region $\mathrm{A}$ was further supported by the demonstration of a unique but short helix 18 for the signature region B (Fig. 2). Initial application of molecular sequencing for identification of Mycobacterium species had attributed the presence of a short helix 18 in region $\mathrm{B}$ to be a feature of rapidly growing mycobacteria. However, the short helix 18 has since been revealed in a number of slow-growing mycobacteria noted to be genetically similar to $\mathrm{Myco}$ - 


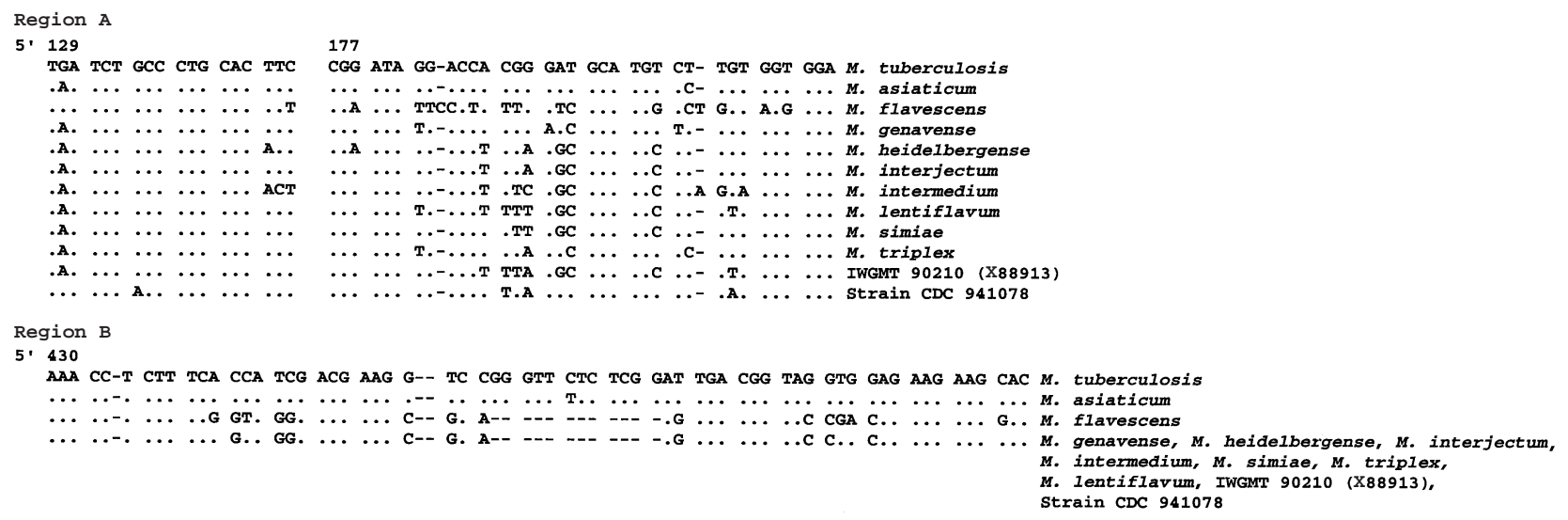

Fig. 2. Alignment of $16 S$ rRNA gene segment for portions of signature regions $A$ and $B$ from selected mycobacteria. The slow-growing mycobacterium reference sequence is $M$. tuberculosis. The rapidly growing mycobacterium reference sequence is Mycobacterium flavescens. Nucleotide positions are noted by comparison with the Escherichia coli numbering scheme. Dots indicate matches, dashes indicate deletions.

bacterium simiae and this feature has been suggested to represent a distinct molecular signature characteristic of this group. (Kirschner et al., 1993; Böttger et al., 1993; Meier et al., 1993; Springer et al., 1993; Tortoli et al., 1997). The unique data from signature region $\mathrm{A}$ and the unusual but characteristic molecular signature of region B, combined with the characteristic slow growth of the study isolates suggested a novel $\mathrm{Myco}-$ bacterium group.

A similarity search of GenBank for related sequences with 1321 continuous nucleotides of the consensus strand revealed $99 \cdot 2 \%$ similarity to a deposited sequence determined from an uncharacterized mycobacterium isolate. The sequence originated from examination of a single isolate in a study of unusual slowly growing mycobacterium strains conducted by the International Working Group on Mycobacterial Taxonomy (IWGMT), strain number 90210, GenBank accession number X88913 (Wayne et al., 1987). However, dissimilar nucleotides were shown for the IWGMT isolate compared to the study isolates, including eight significant nucleotides in the signature or hypervariable region A (Fig. 2). Moreover, this unavailable IWGMT isolate was biochemically distinct from the study isolates and had been reported to be non-pigmented, negative for catalase activity and positive for Tween hydrolysis. Further, genetic comparison with the phenotypically similar $M$. asiaticum demonstrated an overall difference of 49 nucleotides in the $16 \mathrm{~S}$ rDNA strand with six occurring in signature region A. Further, phylogenetic analysis of the DNA consensus sequence was done by alignment with other representative mycobacteria sequences deposited in GenBank for a region of 1317 nucleotides. This sequence was used to construct the phylogenetic dendrogram shown in Fig. 3. The unique position of the study isolates was confirmed to be intermediate between slow- and rapidly growing mycobacteria on a branch with other slow-growing mycobacteria that exhibit a short helix 18 in signature region B (Figs 2 and 3). This unique position branched off the root of the other slow-growing species and indicated a phylogenetically older group than most slow-growers. Phylogenetically, the most closely related known Mycobacterium species to the study isolates and their similarities were: M. simiae, 99.0\%; Mycobacterium heidelbergense, $98.8 \%$; Mycobacterium triplex $98.7 \%$; Mycobacterium intermedium, 98.5\%; Mycobacterium genavense, $98.4 \%$; and Mycobacterium interjectum, $98 \cdot 1 \%$. The phenotypically similar $M$. asiatiacum demonstrated a relatively low similarity value, $97 \cdot 3 \%$. All other known Mycobacterium species had a genetic similarity less than $97 \cdot 1 \%$.

The Mycobacterium species found to be on this intermediate branch of the phylogenetic tree have been reported genetically similar. It was important to note that chemically each of these species produced a distinctive HPLC mycolic acid pattern that was complex and multiple-clustered. This was unlike the mycolic acid pattern of the study group, which was a simple, single-cluster MAPS (Fig. 1). The reliability of the tree branching pattern was tested by the construction of a majority-rule consensus tree for 100 replicates and indicated a moderate bootstrap value, $85 \%$ (Felsenstein, 1985; Hillis \& Bull, 1993). Both the phylogenetic relationships and chemotaxonomical data were supportive of a novel Mycobacterium taxon.

\section{Description of Mycobacterium kubicae sp. nov.}

Mycobacterium kubicae (ku.bi'cae. N.L. gen. n. kubicae of Kubica, to honour the contributions of George P. Kubica, an exceptional American mycobacteriologist, mentor and teacher).

The bacillus stains acid-alcohol-fast and produces mature growth in $21 \mathrm{~d}$ at temperatures between 33 and $37^{\circ} \mathrm{C}$. Cells are typically rod-shaped, with some 


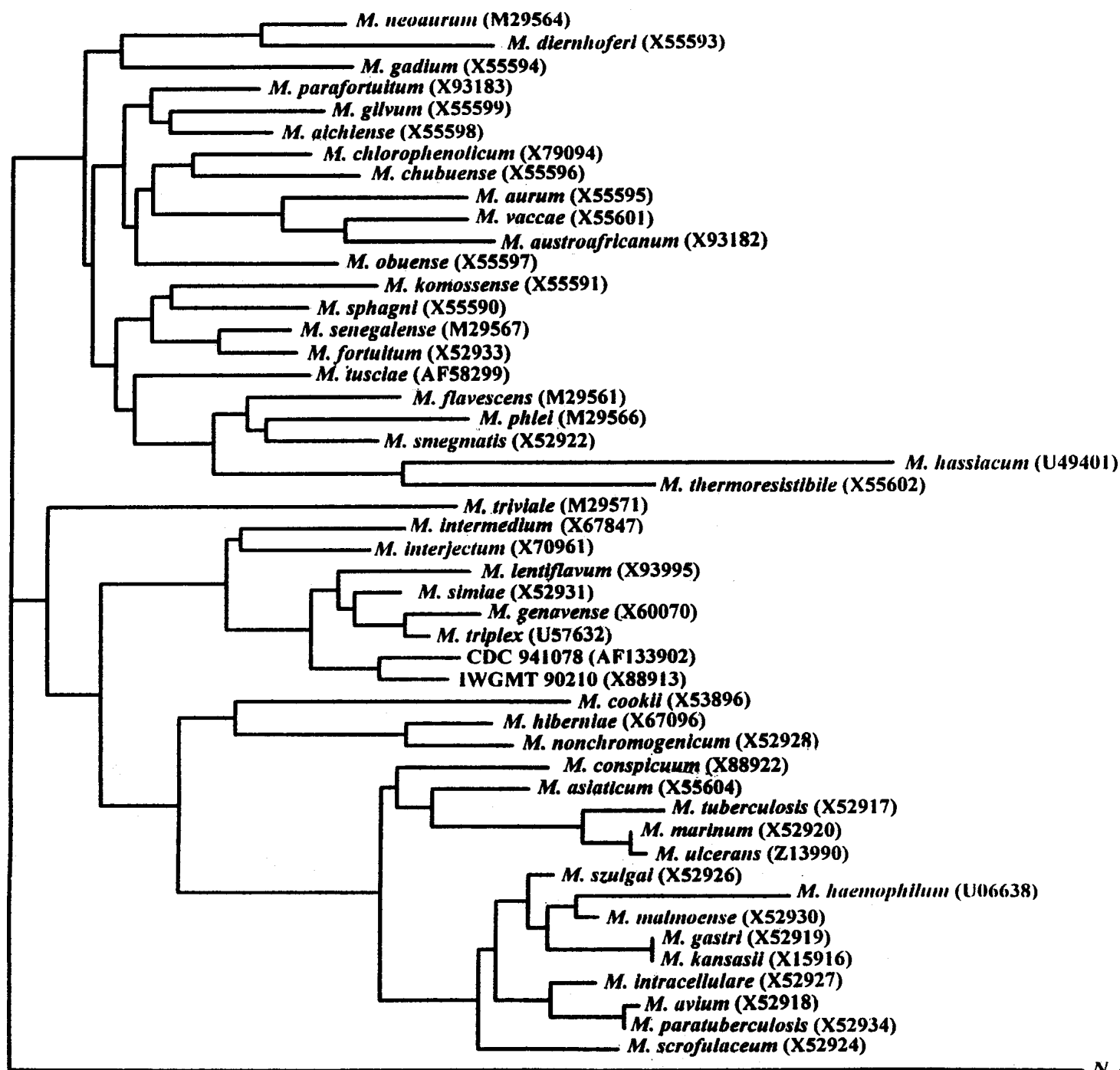

N. asteroides (X57949)

Fig. 3. Phylogenetic relationships of selected species belonging to the genus Mycobacterium based on $16 \mathrm{~S}$ rRNA gene sequences. The tree was rooted with Nocardia asteroides as an outgroup. GenBank accession numbers are shown in parentheses.

coccoid forms, but without branches or aerial mycelia. Colonies grow smooth and domed on MiddlebrookCohn 7H11, film-like on $\mathrm{L}-\mathrm{J}$ and produce a yellow pigment in the dark. The organism produces $>45 \mathrm{~mm}$ foam in the semi-quantitative catalase test. It shows variable results for arylsulfatase at $3 \mathrm{~d}$, and is negative for Tween 80 hydrolysis, nitrate reductase and urease. Isolates are resistant to amikacin and rifampin, partially resistant to ciprofloxacin, cycloserine, ethambutol, isoniazid, rifabutin and streptomycin, and susceptible to clarithromycin, clofazimine and ethionamide. Mycolic acids are long-carbon-chain-length, nonoxygenated alpha mycolates and oxygenated keto and methoxy mycolates, and produce a single-cluster MAPS by HPLC, typical of mycobacteria. Phylogenetically, the 16S rRNA gene sequence is unique and the species occupies a characteristic, intermediate position between slow- and rapidly growing myco- bacteria. The GenBank accession number for the $16 \mathrm{~S}$ rRNA gene sequence is AF133902. The type strain is CDC $941078^{\mathrm{T}}$ from human sputum (= ATCC $700732^{\mathrm{T}}=$ CIP $106428^{\mathrm{T}}$ ).

\section{REFERENCES}

Butler, W. R., Floyd, M. M., Silcox, V. \& 9 other authors (1996). Standardized Method for HPLC Identification of Mycobacteria. Atlanta, GA: Centers for Disease Control and Prevention.

Butler, W. R., Floyd, M. M., Silcox, V. \& 9 other authors (1999). Mycolic Acid Pattern Standards for HPLC Identification of Mycobacteria. Atlanta, GA: Centers for Disease Control and Prevention.

Böttger, E. C., Hirschel, B. \& Coyle, M. B. (1993). Mycobacterium genavense sp. nov, Int J Syst Bacteriol 43, 841-843.

Duffey, P. S., Guthertz, L. S. \& Evans, G. C. (1996). Improved rapid identification of mycobacteria by combining solid-phase 
extraction with high-performance liquid chromatography analysis of BACTEC cultures, J Clin Microbiol 34, 1939-1943.

Edwards, U., Rogall, T., Blöcker, H., Emde, M. \& Böttger, E. C. (1989). Isolation and direct sequencing of entire genes. Characterization of a gene coding for $16 \mathrm{~S}$ ribosomal RNA, Nucleic Acids Res 17, 7843-7853.

Felsenstein, J. (1985). Confidence limits on phylogenies: an approach using the bootstrap, Evolution 39, 783-791.

Felsenstein, J. (1993). PHYLIP: Phylogeny Inference Package. Department of Genetics, University of Washington, Seattle, WA, USA.

Floyd, M. M., Guthertz, L. S., Silcox, V. A., Duffey, P. S., Jang, Y., Desmond, E. P., Crawford, J. T. \& Butler, W. R. (1996). Characterization of an SAV organism and proposal of Mycobacterium triplex sp. nov, J Clin Microbiol 34, 2963-2967.

Glickman, S. E., Kilburn, J. O., Butler, W. R. \& Ramos, L. S. (1994). Rapid identification of mycolic acid patterns of mycobacteria by high performance liquid chromatography using pattern recognition software and a Mycobacterium library, $J$ Clin Microbiol 32, 740-745.

Hillis, D. M. \& Bull, J. J. (1993). An empirical test of bootstrapping as a method for assessing confidence in phylogenetic analysis, Syst Biol 42, 182-192.

Jukes, T. H. \& Cantor, C. R. (1969). Evolution of protein molecules. In Mammalian Protein Metabolism, vol. 3, pp. 21-132. Edited by H. N. Munro. New York: Academic Press.

Kent, P. T. \& Kubica, G. P. (1985). Public Health Mycobacteriology. A Guide for the Level III Laboratory, US Department of Health and Human Services publication. Atlanta, GA: Centers for Disease Control and Prevention.

Kinyoun, J. J. (1915). A note on Uhlenhuth's method for sputum examination for tubercle bacilli, Am J Public Health 5, 867-870.

Kirschner, P., Meier, A. \& Böttger, E. C. (1993). Genotypic identification and detection of mycobacteria - facing novel and uncultured pathogens. In Diagnostic Molecular Microbiology: Principles and Applications, pp. 173-190. Edited by D. H. Persing, T. F. Smith, F. C. Tenover \& T. J. White. Washington DC: American Society for Microbiology.

Lévy-Frébault, V., Goh, K.-S. \& David, H. L. (1986). Mycolic acid analysis for clinical identification of Mycobacterium avium and related mycobacteria, J Clin Microbiol 24, 835-839.
Meier, A., Kirschner, P., Schröder, H., Wolters, J., Kroppenstedt, M. \& Böttger, E. C. (1993). Mycobacterium intermedium sp. nov, Int J Syst Bacteriol 43, 204-209.

Ramos, L. S. (1994). Characterization of mycobacteria species by HPLC and pattern recognition, J Chromatogr Sci 32, 219-227.

Rogall, T., Wolters, J., Flohr, T. \& Böttger, E. C. (1990). Towards a phylogeny and definition of species at the molecular level within the genus Mycobacterium, Int J Syst Bacteriol 40, 323-330.

Springer, B., Kirschner, P., Rost-Meyer, G., Schröder, H., Kroppenstedt, R. M. \& Böttger, E. C. (1993). Mycobacterium interjectum, a new species isolated from a patient with chronic lymphadenitis, J Clin Microbiol 31, 3083-3089.

Stackebrandt, E. \& Smida, J. (1988). The phylogeny of the genus Mycobacterium as determined by $16 \mathrm{~S}$ rRNA sequences, and development of DNA probes. In Biology of Actinomycetes, pp. 244-250. Tokyo: Japan Scientific Societies Press.

Stahl, D. A. \& Urbance, J. W. (1990). The division between fastand slow-growing species corresponds to natural relationships among the mycobacteria, J Bacteriol 172, 116-124.

Thibert, L. \& LaPierre, S. (1993). Routine application of highperformance liquid chromatography for identification of mycobacteria, J Clin Microbiol 31, 1759-1763.

Tortoli, E., Bartoloni, A., Burrini, C., Mantella, A. \& Simonetti, M. T. (1995). Utility of high-performance liquid chromatography for identification of mycobacterial species rarely encountered in clinical laboratories, Eur J Clin Microbiol Infect Dis 14, 240-243.

Tortoli, E., Piersimoni, C., Kirschner, P. \& 10 other authors (1997). Characterization of mycobacterial isolates phylogenetically related to, but different from Mycobacterium simiae. J Clin Microbiol 35, 697-702.

Wayne, L. G., Brenner, D. J., Colwell, R. R. \& 9 other authors (1987). International Committee on Systematic Bacteriology. Report of the ad hoc committee on reconciliation of approaches to bacterial systematics. Int J Syst Bacteriol 37, 463-464.

Wayne, L. G., Good, R. C., Böttger, E. C. \& 19 other authors (1996). Semantide- and chemotaxonomy-based analyses of some problematic phenotypic clusters of slowly growing mycobacteria, a cooperative study of the International Working Group on Mycobacterial Taxonomy. Int J Syst Bacteriol 46, 280-297. 